\title{
Erratum to: Genetic diversity and population structure of the primary malaria vector Anopheles sinensis (Diptera: Culicidae) in China inferred by cox 1 gene
}

Xinyu Feng ${ }^{1,2+}$, Libin Huang ${ }^{3+}$, Lin Lin², Manni Yang ${ }^{2}$ and Yajun Ma ${ }^{2^{*}}$

\section{Erratum}

After the publication of this work [1] it was noticed that there were errors in a number of coordinates in Table 1. The corrected table is shown below with the updated coordinates for population codes JX, SD, HAN, GX and LN.

\footnotetext{
Author details

${ }^{1}$ WHO Collaborating Center for Tropical Diseases, Key Laboratory of Parasite and Vector Biology, Ministry of Public Health, National Institute of Parasitic Diseases, Chinese Center for Disease Control and Prevention, Shanghai 200025, China. ${ }^{2}$ Department of Tropical Infectious Disease, Second Military Medical University, Shanghai 200433, China. ${ }^{3}$ Second Military Medical

University Press, Shanghai 200433, China.
}

Received: 17 February 2017 Accepted: 17 February 2017

Published online: 02 March 2017

\section{Reference}

1. Feng $X$, Huang L, Lin L, Yang M, Ma Y. Genetic diversity and population

structure of the primary malaria vector Anopheles sinensis (Diptera: Culicidae) in China inferred by cox1 gene. Parasit Vectors. 2017;10:75.

\footnotetext{
*Correspondence: yajun_ma@163.com

${ }^{\dagger}$ Equal contributors

${ }^{2}$ Department of Tropical Infectious Disease, Second Military Medical

University, Shanghai 200433, China
} 
Table 1 Collection information of Anopheles sinensis populations in this study

\begin{tabular}{|c|c|c|c|c|}
\hline Population code & Collection site & Date & Coordinates & Sample size \\
\hline$\overline{\mathrm{AH}}$ & Hefei, Anhui & July 2006 & $31^{\circ} 49^{\prime} \mathrm{N}, 117^{\circ} 13^{\prime} \mathrm{E}$ & 29 \\
\hline$H B$ & Wuhan, Hubei & August 2006 & $30^{\circ} 35^{\prime} \mathrm{N}, 114^{\circ} 17^{\prime} \mathrm{E}$ & 25 \\
\hline FJ & Jianyang, Fujian & September 1997 & $27^{\circ} 20^{\prime} \mathrm{N}, 118^{\circ} 06^{\prime} \mathrm{E}$ & 30 \\
\hline CQ & Kaixian, Chongqing & July 2008 & $29^{\circ} 34^{\prime} \mathrm{N}, 106^{\circ} 32^{\prime} \mathrm{E}$ & 24 \\
\hline \multirow[t]{3}{*}{ HEN } & Nanyang, Henan & August 2007 & $32^{\circ} 59^{\prime} \mathrm{N}, 112^{\circ} 31^{\prime} \mathrm{E}$ & 39 \\
\hline & Guangshui, Hubei & June 2007 & $31^{\circ} 37^{\prime} \mathrm{N}, 113^{\circ} 49^{\prime} \mathrm{E}$ & 6 \\
\hline & Shuizhou, Hubei & June 2007 & $31^{\circ} 41^{\prime} \mathrm{N}, 113^{\circ} 22^{\prime} \mathrm{E}$ & 5 \\
\hline JS & Wujing, Jiangsu & July 1997 & $31^{\circ} 48^{\prime} \mathrm{N}, 119^{\circ} 58^{\prime} \mathrm{E}$ & 40 \\
\hline $\mathrm{GZ}$ & Kaili, Guizhou & August 2007 & $26^{\circ} 34^{\prime} \mathrm{N}, 107^{\circ} 58^{\prime} \mathrm{E}$ & 26 \\
\hline$J X$ & Yongxiu, Jiangxi & September 2009 & $29^{\circ} 01^{\prime} \mathrm{N}, 109^{\circ} 48^{\prime} \mathrm{E}$ & 28 \\
\hline GD & Zhuhai, Guangdong & October 2007 & $22^{\circ} 16^{\prime} \mathrm{N}, 113^{\circ} 34^{\prime} \mathrm{E}$ & 46 \\
\hline \multirow[t]{3}{*}{ SD } & Jining, Shandong & July 2007 & $35^{\circ} 41^{\prime} \mathrm{N}, 116^{\circ} 34^{\prime} \mathrm{E}$ & 14 \\
\hline & Yutai, Shandong & July 2000 & $35^{\circ} 01^{\prime} \mathrm{N}, 116^{\circ} 38^{\prime} \mathrm{E}$ & 13 \\
\hline & Linshu, Shandong & July 2000 & $34^{\circ} 55^{\prime} \mathrm{N}, 118^{\circ} 38^{\prime} \mathrm{E}$ & 10 \\
\hline HAN & Qiongzhong, Hainan & August 2010 & $19^{\circ} 28^{\prime} \mathrm{N}, 106^{\circ} 51^{\prime} \mathrm{E}$ & 24 \\
\hline GX & Tiane, Guangxi & July 2005 & $25^{\circ} 06^{\prime} \mathrm{N}, 107^{\circ} 10^{\prime} \mathrm{E}$ & 18 \\
\hline \multirow[t]{2}{*}{ LN } & Suizhong, Liaoning & August 2008 & $40^{\circ} 29^{\prime} \mathrm{N}, 120^{\circ} 01^{\prime} \mathrm{E}$ & 7 \\
\hline & Xingcheng, Liaoning & August 2008 & $40^{\circ} 36^{\prime} \mathrm{N}, 120^{\circ} 45^{\prime} \mathrm{E}$ & 8 \\
\hline SC & Pujiang, Sichuan & July 1997 & $30^{\circ} 19^{\prime} \mathrm{N}, 103^{\circ} 51^{\prime} \mathrm{E}$ & 33 \\
\hline YN & Yanjin, Yunnan & July 2006 & $28^{\circ} 10^{\prime} \mathrm{N}, 104^{\circ} 23^{\prime} \mathrm{E}$ & 28 \\
\hline
\end{tabular}

